\title{
Sound absorption properties of aluminum sponges manufactured by infiltration process
}

\author{
Patricia Fernández M., a, Luis J. Cruz R., ${ }^{2, b}$, Luis E. García-Cambronero ${ }^{3, c}$, \\ Cesar Díaz ${ }^{4, d}$ and María Angeles Navacerrada ${ }^{4, e}$ \\ ${ }^{1}$ Industrial Engineering Faculty, GINUMA, Universidad Pontificia Bolivariana, Colombia \\ ${ }^{2}$ Mechanical Engineering Faculty, GINUMA, Universidad Pontificia Bolivariana, Colombia \\ ${ }^{3}$ Universidad Politécnica de Madrid, ETSI Minas, Spain \\ ${ }^{4}$ Universidad Politécnica de Madrid, ETSI Arquitectura, Spain \\ apatricia.fernandez@correo.upb.edu.co, 'luis.cruz@upb.edu.co. '9uis.gcambronero@upm.es, \\ dcesar.diaz.sanchidrian@upm.es, ${ }^{\circ}$ mdelosangeles.navacerrada@upm.es
}

Keywords: Sound absorption, aluminum sponges, standing wave method, salt preform, infiltration process.

Abstract. In this paper, the sound absorption properties of aluminum sponges manufactured by
infiltration process have been studied. The results show that the sound absorption factor $\alpha$ changes in
function of pore size. Additionally, the sound absorption factor $\alpha$ was sensitive to the frequency range
measured and it was depending of the thickness sample. It was found that the interconnected porosity
plays an important role increasing the sound absorption properties of the aluminum sponges studied.

\section{Introduction}

Cellular metals are a new kind of materials that introduce concepts such as metal sponge and metal foam, it is mean, metals that possess open and closed porosity, respectively [1]. In particular, aluminum sponges exhibit a lot of excellent functional properties, such as heat transference, catalysis supporting, vibration reduction, sound absorption and permeability to fluids [2]. In this sense, they are very attractive to many applications in several fields such as automotive, aerospace, construction and so on [3].

It is possible to obtain different porous structures depending of the fabricating technique. In general, three basic methods have been reported: powder metallurgy, electrodeposition and foundry methods [4]. The infiltration method belongs to the latest technique, and it was used to obtain the aluminum sponges for this study. In this case, a salt preform was infiltrated with melted aluminum using vacuum pressure [5].

With reference to sound absorption properties of cellular metals, $\mathrm{Lu} \mathrm{[6]}$ studied foams named Alporas, determining that they are not good sound absorbers due to their closed porous structure. Kim [7] reported a good behavior to sound insulation of foams obtained by addition of foaming agent directly to the melted metal. Berg [8] studied sponges produced by replication process using polymer preforms, obtaining an average sound absorption coefficient around 0.80 . Wu [9] compared the sound absorption between sponges and foams produced with aluminum alloy A356 reinforced by SiC particles, achieving absorption coefficients about 0.90 near to frequencies of $1600 \mathrm{~Hz}$. Göhgler [10] explored the sound insulation for vehicular exhaust system with foams fabricated with hollow spheres, obtaining poor results.

Using impedance tube technique, Nakajima studied the sound absorption capacity in magnesium foams lotus type, showing that the coefficient increasing with the increasing of frequency [11]. In the present study, the standing wave tube was the test used to evaluate the sound absorption properties of aluminum sponges. The main feature to analyze in this study is the influence of the pore structure on the sound absorption coefficient. 


\section{Experimental procedures}

Preform infiltration process. The process used to produce the aluminum sponges consists in three steps: i) preform elaboration of $\mathrm{NaCl}$ (common salt), ii) preform infiltration with the liquid aluminum, under vacuum pressure and temperature of $700^{\circ} \mathrm{C}$ and, iii) the resulting $\mathrm{Al} / \mathrm{NaCl}$ composites were then machined and the salt was removed by dissolution in distilled water, leaving the porous structure discovered. The aluminum matrix was an AlSiMg alloy and the $\mathrm{NaCl}$ used was common salt sieved to obtain particles of controlled size of $2.0 \mathrm{~mm}, 1.0 \mathrm{~mm}$ and $0.5 \mathrm{~mm}$.

Structure and density. The particle size of the $\mathrm{NaCl}$ must to be selected according to the intended cell size of the final sponge. In this case, the macrostructure of the sponges was examined by mean scanning electron microscopy and optical microscopy. Porosity percentage was measured by an ACCUPIC 1330 gas pycnometer, and relative density is the relation between density of porous sample and density of solid aluminum ( $\rho$ relative $=\rho$ porous sample $/ \rho$ solid aluminum).

Sound absorption tests. The sound absorption factor $\alpha$ was measured by the standing wave method within the frequency range of $500 \sim 6400 \mathrm{~Hz}$. This test included an impedance tube type 4206, Pioneer A-305 R sound generator, $B \& K$ loudspeaker type 4186 and probe. Cylindrical samples of 29 $\mathrm{mm}$ in diameter and, $20 \mathrm{~mm}$ and $10 \mathrm{~mm}$ in thickness were used. It is important to take into account that the air gap layer between the sample and the rigid wall was zero. The sound absorption coefficient $(\alpha)$ measures the fraction of the energy of a sound wave which is absorbed when it is incident on the surface of a material and it has been expressed by Eq. 1 :

$$
\alpha=\left(\frac{E_{i}-E_{r}}{E_{i}}\right)
$$

where $E_{\mathrm{i}}$ is the whole energy of incident sound, and $E_{\mathrm{r}}$ is the energy of the reflective sound. The average absorption coefficients were calculated by conducting three replicate measurements for each sample.

\section{Results and discussion.}

Aluminum sponges revealed a structure with multi-angular pores interconnected uniformly, such as is showing in Fig. 1. Depending on size of salt particles, was possible to obtain sponges with three pores sizes: $0.5 \mathrm{~mm}, 1.0 \mathrm{~mm}$ and $2.0 \mathrm{~mm}$. The value of porosity percentage was around of $65 \%$, and this is corresponding to the value of 0.35 obtained for the relative density.
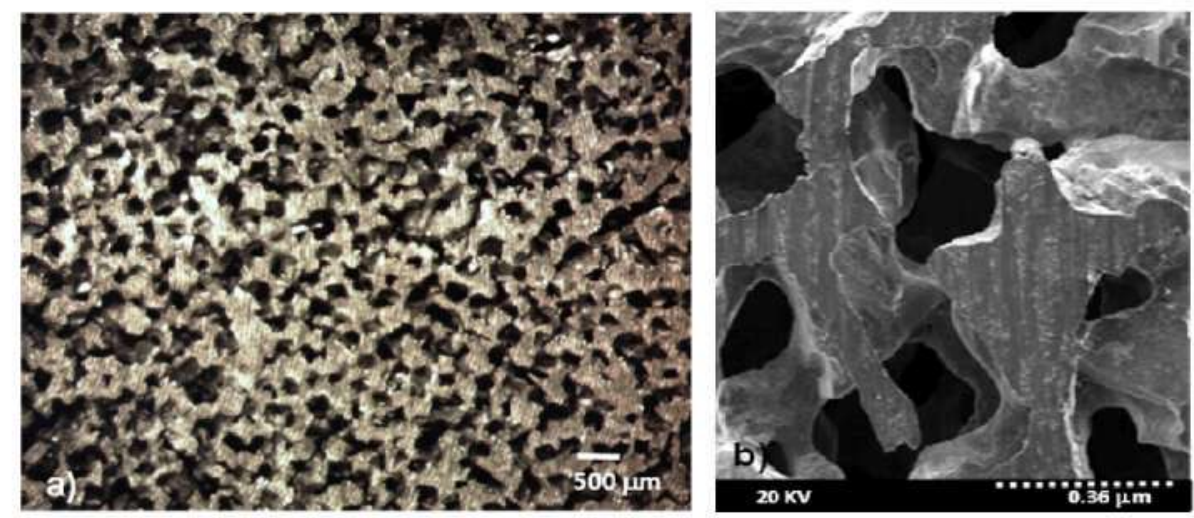

Fig. 1. Aluminum sponges: a) Optical image of macrostructure, b) SEM image of pores, interconnection, morphology and size. 
It can be observed that both pore morphology and pore size is nearly the morphology and size of salt particles used in the preforms.

\section{Sound absorption properties.}

As can be seen in Fig. 2, the most interesting feature in all curves of frequency versus sound absorption coefficient is the presence of a maximum peak for each pore size. Likewise, it is noted that each sample has a selective behavior with reference to the frequency, presenting an independent peak for each case, and similar frequencies for samples with $1.2 \mathrm{~mm}$ and $2.0 \mathrm{~mm}$ of pore size. In the same sense, samples with the smaller pore size $(0.5 \mathrm{~mm})$ had the maximum peak of $\alpha$ in $0.96(-4330 \mathrm{~Hz})$ and $0.87(\sim 2230 \mathrm{~Hz})$ for the two thicknesses of $10 \mathrm{~mm}$ and $20 \mathrm{~mm}$, respectively.
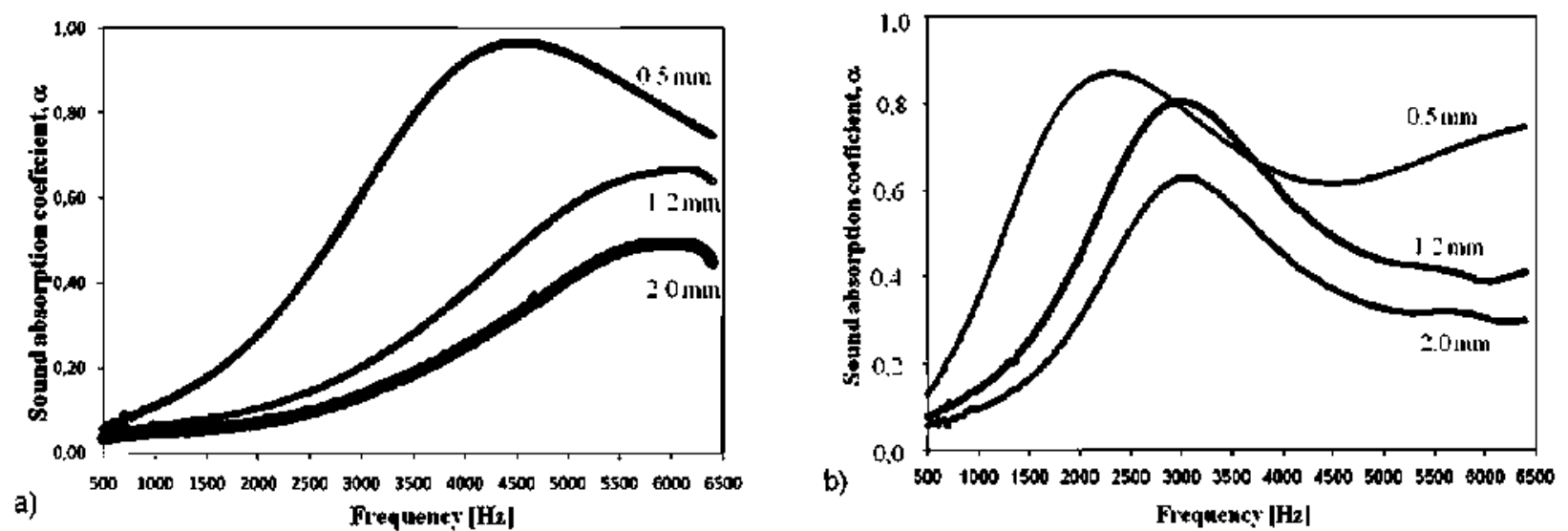

Fig. 2. Sound absorption coefficient $\alpha$ as a function of frequency and pore size a) sample thickness: 10 $\mathrm{mm}$, b) sample thickness: $20 \mathrm{~mm}$.

In reference to the sample thickness, the major characteristic of the behavior of the aluminum sponges was the displacement of the absorption peaks, whose maximum were originated approximately in a half of the frequency for the samples with larger thickness.

Compared with aluminum foams (closed cells) reported by other authors [8], it was found that aluminum sponges have higher sound absorption capacity at similar frequencies. It could be due to the celllular structure characterized by pore interconnection and intricated paths, that allows the sound atenuation inside the sponge. The experimental results indicate that these samples having the same porosity $(\sim 65 \%)$, had similar behavior, it is mean; they showed similar shape of peaks and had a maximum peak.

\section{Discussion.}

It is suggested that good acoustic behavior observed in the samples with smaller pore, may be associated specifically with the phenomenon of internal vibration of the sound wave. When the sound wave penetrates the material and once inside, the amplitude of vibration of the air molecules is progressively damped due to the friction with the cavities surfaces, and if the path has a greater number of these cavities, then this lead to a greater dissipation of the sound wave, resulting ultimately in a greater absorption of sound. $\mathrm{Lu}[6]$ calls this behavior as acoustic energy dissipation by friction, which states that becomes more relevant to pore diameters less than $0.5 \mathrm{~mm}$, such as was demonstrated in this work for the sponges with smaller pores.

Any material must have a sound absorption coefficient above 0.90 for to be considered as a good sound insulator. On the whole, aluminum sponges showed good behavior as sound absorption materials at higher frequencies. This feature is in agreement with other porous sound absorption 
materials, and due to the interconnected pores, the aluminum sponges manufactured by infiltration process are cellular metals that are potentially useful for acoustic insulation. In this sense, it could be present best qualities respect to the foam metals, such as is reported by Lu [6] and Miyoshi [12]. These aluminum sponges are highly efficient in sound absorption, where incoming sound is reflected inside the foam among the pores, and the pore surfaces vibrate converting the sound into heat. In this case, the porous structure in these sponges leads to efficient absorption of vibration energy caused by sound. On the other hand, at similar porosity, the coefficient $\alpha$ varies with frequency and it is function of material thickness and pore size.

\section{Summary}

It was found that the sound absorption coefficients of the samples having similar porosity and different average pore sizes were smaller within lower frequency range. With the increase of frequency, their coefficients increased rapidly reaching a peak in each sample, and then dropped again. In general, the samples with smaller pores sizes had better sound absorption properties around frequency range of $2230-4300 \mathrm{~Hz}$. Finally, the friction that reduce the sound waves, becomes more significant if the pore size that spans the entire sponge is small, even for small sample thicknesses.

\section{Acknowledgment}

The present authors wish to thank the financial support provided by COLCIENCIAS by the Project $\mathrm{N}^{\circ} 1210-452-21201$, and to UPB for partial financial support by CIDI-UPB Project 334A-12/08-18.

\section{References}

[1] L.J. Gibson and M.F. Ashby: Cellular solids: structure and properties, (Cambridge University Press, Cambridge, UK, 1997).

[2] V.N. Antsiferov, A.M. Makarov and V.D. Khramtsov: Adv. Eng. Mater Vol. 7, (2005), p. 77.

[3] J. Banhart: Prog. Mater. Sci Vol. 46, (2001) p. 559.

[4] H. Wadley: Adv. Eng. Mater Vol. 4, (2002), p. 726.

[5] C. San Marchi and A. Mortensen, in: Handbook of Cellular Materials - Production, Processing, Applications, Chapter 2.6, Wiley-VCH, Weinheim, (2002).

[6] T.J. Lu, A. Hess and M.F. Ashby: J. Appl. Phys Vol. 85, (1999), p. 7528.

[7] S.Y. Kim, B.Y. Hur, K.C. Kwon, S.H. Cho, C.Y. Lim, Y.M. Yoo and M.H. Lee: Proceedings of Cellular Metals: Manufacture, properties, applications MetFoam, Berlin, (2003), p. 469.

[8] A. Berg, W.Y. Maysenhölder and M. Haesche, in: Proceedings of Cellular Metals: Manufacture, properties, applications MetFoam, Berlin, (2003), p. 487.

[9] J. Wu, Ch. Li, D. Wang and M. Gui: Compos. Sci. Technol Vol. 63, (2003), p. 569.

[10]H. Göhler, P. Löthman, U. Waag, H. Schneidereit, E. Bernhard in: Proceedings of Cellular metals and metal foaming technology 2nd Int. Conf., Bremen, (2001), p. 391.

[11]H. Nakajima, T. Ikeda and S. K. Hyun: Adv. Eng. Mater Vol. 6, (2004), p. 377.

[12] T. Miyoshi, M. Itoh, S. Akiyama and A. Kitahara: Adv. Eng. Mater Vol. 2, (2000), p. 179. 